\title{
A GESTÃo ESCOLAR E AS POSSIBILIDADES DE DEMOCRATIZAÇÃO DA ORGANIZAÇÃO DO TRABALHO PEDAGÓGICO.
}

Maria da Conceição Barra

Ada Medeiros

\section{RESUMO}

O presente artigo versa sobre a temática da "A gestão escolar e as possibilidades de democratização da organização do trabalho pedagógico". Sendo assim, estabelecemos como objetivo geral: Analisar os desafios e possibilidades para efetivação da gestão democrática escolar; e específicos: Refletir sobre o contexto histórico de produção das concepções democráticas de gestão da sociedade e da escola; Conhecer os desafios para que os processos democráticos da gestão escolar sejam consolidados tal como disciplina a LDB; Identificar os mecanismos de participação que foram criados para dar visibilidade à gestão democrática. Adotamos a metodologia de pesquisa bibliográfica, orientada a partir da revisão de literatura que teve como primeira etapa, o levantamento da bibliografia, seleção do referencial teórico, das citações e dados necessários para a reflexão crítica da realidade do processo de gestão escolar. Constatamos que, a gestão escolar na perspectiva democrática é possível, mas algumas condicionalidades são necessárias para que ela se efetive: Conselho Escolar Eleição para Gestor da instituição e Projeto Político Pedagógico. É importante destacar que todos esses elementos descritos são dispositivos que prescindem da participação efetiva e crítica da comunidade, contudo, a existência dos mesmos na instituição escolar não significa que as práticas serão democráticas, mas a ausência dos mesmos inviabiliza que a comunidade participe efetivamente das ações da escola.

PALAVRAS-CHAVE: Gestão Democrática. Conselho Escolar. Eleição Para Diretor. Projeto Político Pedagógico.

\section{INTRODUÇÃO}

Considerando o tempo histórico, notamos que a concepção de gestão escolar numa perspectiva democrática é um fenômeno bem recente que data do contexto da abertura política e econômica brasileira, com o fim da ditadura militar. Contudo, têm sido vastas as produções no campo da gestão, muito embora estes tenham centrando suas análises a partir de um viés global, desconsiderando as especificidades histórica e contextual de cada espaço em que os processos de gestão são desenvolvidos.

Nesse sentido, são recorrentes os esforços de pesquisadores em buscar conceituar e apresentar um modelo de gestão que julguem ser a fórmula secreta para a resolução dos problemas administrativos que se apresentam a escola. O que notamos ao realizar uma pesquisa bibliográfica é uma grande crença na 
possibilidade da gestão democrática (modelo de gestão defendido pela maioria dos teóricos), mas que não se materializa em razão de inúmeros fatores e condições que são necessárias ao exercício da participação, tais como o Conselho Escolar (CE), Eleição para Diretor (ED), Projeto Político Pedagógico (PPP).

Nesse sentido, adotamos como objetivo geral nesse estudo: Analisar os desafios e possibilidades para efetivação da gestão democrática escolar. Como objetivos específicos: Refletir sobre o contexto histórico de produção das concepções democráticas de gestão da sociedade e da escola; Conhecer os desafios para que os processos democráticos da gestão escolar sejam consolidados tal como disciplina a LDB; Identificar os mecanismos de participação que foram criados para dar visibilidade à gestão democrática. Para que fosse possível a construção desse artigo, trabalhamos com a pesquisa bibliográfica, no qual por meio do levantamento bibliográfico tivemos a possibilidade de compreender os conceitos concernentes a gestão escolar e seus pressupostos democráticos. Assim, selecionamos os autores que se aproximaram da nossa proposta de debate, para que assim, os dados necessários para as reflexões sobre a realidade fossem coletados.

Sendo assim, ao longo desse artigo constatamos que a gestão escolar na perspectiva democrática é possível, mas algumas condicionalidades são necessárias para que ela se efetive, como por exemplo, fortalecimento do Conselho Escolar com a participação efetiva e autônoma da comunidade escolar, eleição para gestor da instituição, pois oportuniza aos sujeitos da comunidade escolherem seu representante na gestão da escola e por fim, elaboração coletiva do projeto político pedagógico, que se apresenta como o documento de identidade da escola.

\section{A GESTÃo ESCOLAR E SEUS DESDOBRAMENTOS NO CONTEXTO BRASILEIRO}

A história do Brasil é marcada por um claro momento antidemocrático com a Ditadura Militar, no qual a participação, o direito e liberdade de expressão foram duramente reprimidos. Apesar disso, no plano do discurso, os militares asseguravam ser democráticos e que todas as medidas de dura repressão adotada eram em nome da democracia, ou seja, a ditadura militar se dizia "democrática", enquanto as pessoas que se rebelaram contra o modelo centralizador de administração, passaram a ser considerados "subversivos", comunistas, etc. 
Segundo Fávero (2002, p.87), "a questão da democracia e do período considerado de transição, a pós-Ditadura Militar, nos obriga a pensar o que entendermos por democracia. Qual sua origem histórica e quais a condições atuais de sua realização no Brasil". Do ponto de vista da sociedade mais ampla e de suas instituições, quando se fala do período pós-ditadura no Brasil, frequentemente se reduz o processo à inibição da ação dos aparelhos de coerção do Estado, identificado como um governo historicamente centralizador repressivo, comprometido com interesses e projetos alheios às demandas vitais de sobrevivência da população brasileira.

Com base em Fávero (2002), podemos considerar que estamos vivendo tempo de "anomalia" e perplexidade diante da abrangência e gravidade dos problemas existentes. As políticas educacionais que a serem formuladas e os planos a serem elaborados como proposta aos sérios problemas da educação brasileira exigem a participação de todos os setores interessados, de modo a romper uma tradição de elaboração técnica, restrita aos órgãos educacionais especializados.

Uma visão retrospectiva mostra que do ponto de vista da educação nossa "transição" é muita mais longa que a transição política institucional dos anos 80 . A história mostra dois movimentos de presença dos sujeitos sociais envolvidos. Em primeiro plano as elites, os intelectuais, os governantes. Num movimento do alto para baixo, pondo e dispondo dos meios e recursos para educação, formulando leis, definindo diretrizes, fazendo e refazendo um processo de muita aparência e pouca efetividade para a solução dos problemas básicos da educação (FÁVERO, 2002).

No plano maior, emergente, as demandas sociais mais amplas da população, reenvidando um espaço educativo diferente da escola burguesa (anos 10), educação elementar (anos 20 e 30), escolas secundárias (anos 40 e 50), ensino superior (anos 60 e 70). Nos anos 80, as demandas referem-se a todos os níveis educacionais e, também, os serviços de creches, profissionalização, melhoria de condições das escolas, recuperação da carreira do professor. Nos anos 90, voltamos às demandas de educação básica (fundamental e média) e cresce a ameaça ao ensino superior público gratuito. Em todas as épocas, os setores mais conscientes da sociedade têm cobrado do Estado a educação pública e gratuita e a defesa de suas instituições.

As políticas e planos educacionais, implementados em nível de Estado, acompanham as vicissitudes da sociedade brasileira na falência de não consolidar, 
até hoje, uma sociedade democrática e de não incorporar amplos setores populares a um projeto superior de país.

No limite desta reflexão que, entendemos, deve subsidiar a compreensão do sentido das políticas e planos educacionais e de uma nova lei de diretrizes e base da educação na atualidade, o movimento amplo das políticas educacionais é mais oportuno do que o detalhamento dos planos. (FÁVERO, 2002, p. 95)

Os planos nacionais de educação, num primeiro momento da vida nacional, adquirem o sentido de lei e se aproximam das políticas educacionais de gestação (anos 20 e 30). Num segundo momento, eles são vistos como uma parte do planejamento estabelecido e refletem a relação educação e desenvolvimento econômico (a partir dos anos 40).

Neste sentido, a ideia do plano nacional se esvazia e o plano assume 0 sentido restrito de plano de aplicação de recursos (na LDBEN - Lei n. 4024/61) ou assume a forma de um plano de governo, contendo metas qualitativas e quantitativas que vão subsidiar os planos posteriores. Os planos subsequentes a 1964 saem gradativamente do âmbito dos pedagogos, para os tecnocratas, economistas e engenheiros da "nova" economia nacional dos anos 70 , que se prolonga até os tempos atuais.

Nos anos 90, acompanhamos internacional de ênfase no regate da educação fundamental, que tem seu marco mais importante na Conferência de Jomtien, em 1990, onde ocorre uma retratação do Estado brasileiro em relação à universidade pública, à ciência e à tecnologia.

\begin{abstract}
A centralização política e administrativa autoritária se manifesta na derrota do projeto das forças progressistas na luta pela nova Lei de Diretrizes e Bases da Educação. Os trabalhadores da Educação viram o Projeto da LDBEN ser descaracterizado na lenta tramitação pelo Congresso Nacional (de 1988 a 1996) e ser substituído por um acordo de gabinete que resultou na Lei n. 9.394/96. (FÁVERO, 2002, p. 95)
\end{abstract}

No contexto brasileiro, observamos uma condição de luta pelo poder de nossos representantes, ou seria a premissa de "levar vantagem"? O fato prático, no entanto, está no contexto de que enfrentamos barreiras advindas das condições históricas e sociais, bem como políticas e jurídicas, conforme alerta o professor Carlos Roberto Jamil Cury (2006; 2008; 2009).

De acordo com Cury (2006), é por meio de uma longa e complexa trajetória histórica que vai se constituindo o Estado do Bem-Estar Social. Nesta trajetória, os direitos políticos da universalização do voto foram importante mediação para a 
declaração e, em muitos casos, a garantia de direitos sociais. As lutas conduzidas por movimentos de esquerda sempre reivindicaram a universalidade da cidadania. Em muitos casos, em vista destas universalidades, os direitos foram ampliados, tendo sido sua presença constante na legislação de vários países. Em todos os casos, é firmado o direto à educação escolar como algo especialmente importante para a participação sociopolítica e para o próprio indivíduo (CURY, 2006). Nesse sentido, entendemos que:

\begin{abstract}
A globalização, por sua vez vai incidir sobre o papel exercido pelo Estado e sobre o conjunto dos direitos sociais. Esta arrogância devastadora do capital financeiro internacional sobre os direitos sociais traz consigo a diminuição da importância de determinada arenas públicas como é o caso dos parlamentos e do próprio conceito de Estado-nação como visível realidade do desemprego, da pobreza, da degradação ambiental e da persistência da desigualdade e que, no caso do Brasil, foi mais uma vez revelada no balanço do Instituto Brasileiro de Geografia e Estatística (IBGE) a respeito da década de 90, recentemente publicado na imprensa. (CURY, 2006, p.148).
\end{abstract}

Portanto, é preciso atentar para que as políticas públicas implementadas pela descentralização, atribuindo autonomia às escolas através da gestão democrática, não seja compreendida como desresponsabilização do Estado e sim como uma ação coletiva em que as decisões contemplem as necessidades e perspectivas do contexto em que as instituições escolares se situam.

Contrária à concepção de democracia defendida pelos conservadores liberais, advoga-se em favor de uma perspectiva democrática na qual a finalidade das práticas sejam a valorização da descentralização administrativa, a autogestão do processo de construção do conhecimento, autonomia e participação dos sujeitos nas práticas sociais e escolares. Nesse sentido, tencionamos, o termo democracia e com base em Dalbério (2008), afirmamos que: O termo democracia originou-se do grego, demos que significa "povo", e kratos que representa "poder". Nos termos descritos, democracia representa uma forma de organização política que reconhece a cada sujeito, como membro da comunidade, o direito de participar da direção e da gestão dos assuntos públicos.

Assim, podemos afirmar que democracia é um regime de governo no qual o poder de tomar importantes decisões políticas está com os cidadãos, que são os membros da sociedade. É ao povo ou à comunidade a quem cabe discutir, refletir, pensar e encontrar soluções e intervenções para os seus próprios problemas. Para 
além de uma visão unilateral faz-se necessário recorrer a Cortella (2005) que entende que a democracia da seguinte forma:

[...] não é um fim em si mesma; é uma poderosa e indispensável ferramenta para a construção contínua da cidadania, da justiça social e da liberdade compartilhada. Ela é a garantia do princípio da igualdade irrestrita entre todas e todos [...]. (CORTELLA, 2005, p. 146)

Cortela (2005) explica que a democracia não se limita à construção de ações coletivas focadas, ou mesmo de uma organização que se limita apenas a um setor da sociedade, mas sim a todos os espaços sociais, já que significa principalmente uma reflexão crítica sobre os pressupostos em que está pautada a sociedade.

$\mathrm{Na}$ direção sinalizada acima, cabe refletir sobre os princípios que fundamentam a sociedade nos dias atuais. As legislações vigentes dão conta de que se vive num país democrático, que se pauta numa legislação que determina as regras de um estado democrático de direito, entretanto, sabe-se que ainda se tem que avançar para que se possa de fato conquistar uma sociedade realmente democrática, uma vez que na atual configuração social, encontram-se muitas contradições que evidenciam uma característica dialética à realidade. Pautados nos princípios acima citados, apresenta-se a necessidade de dialogar sobre os conceitos de democracia representativa e democracia participativa.

Entende-se a democracia representativa como sendo o ato de um grupo ou pessoa ser escolhido por dentre outros para ocupar um cargo no qual a finalidade seja a representação dos interesses do povo, ou seja, é atribuir o poder decisório a uma pessoa ou a um pequeno grupo tendo em vista a defesa do interesse do povo, ou pelo menos a sua representação. Há de se ressaltar que na maioria das vezes a escolha desses representantes acontece por meio de uma votação. Na democracia representativa existem os processos eleitorais tanto para cargos legislativos e executivos da esfera política brasileira, como os da educacional (escola). Diante dessas constatações, é pertinente recorrer aos estudos de Marques (2008) ao considerar que:

[...] os processos de democracia representativa não conseguiram dar conta da pluralidade cultural e do reconhecimento de novas identidades, o que exigiu profundas redefinições nas práticas democráticas. Dessa forma, a democracia participativa, que se dá tanto na esfera do Estado quanto na não-estatal, incorpora ao debate político propostas de reconhecimento cultural e inclusão social, visando assegurar o pluralismo e a tolerância, sem o qual (sic) a democracia participativa definha. (MARQUES, 2008, p. 72) 
Nota-se nas considerações de Marques (2008) que a democracia representativa caracteriza o povo como uma organização consultiva, não de maneira constante, mas num longo espaço de tempo (como é o caso das eleições eleitorais que acontecem de quatro em quatro anos).

É importante ressaltar que a democracia representativa tem sua maior expressão na esfera estatal, pois, limita-se à atuação política e administrativa em "favor do povo". Percebe-se nessa prática de democracia a exclusão sumária do povo de uma prática que the é inerente, que é a possibilidade de escolha. Nessa relação o povo passa de detentor do poder, a mero segmento social que está sujeito às decisões de um dirigente (pessoas políticas como: Presidente, Governador, Prefeito e outros), ou seja, passa a ser dirigido.

De acordo com Bobbio (1996) democracia é um sistema político no qual o poder é exercido por todos de maneira crítica e coletiva, ou seja, neste sistema as regras partem do consenso coletivo. Dessa forma, a democracia é um sistema estritamente dialético, pois parte do princípio da contradição, ou mesmo do conflito de ideia, já que os sujeitos pertencentes a este sistema são críticos e nem sempre primam pela unanimidade nas decisões, entretanto, é necessário que haja o consenso e que prevaleça os desejos da maioria e não apenas de um pequeno grupo como estabelecido na democracia representativa.

No sentido de garantir o bem-estar social, apresenta-se nesse contexto a prática educativa, pois essa seria a melhor maneira de conscientizar os sujeitos dos papeis que desempenham na sociedade. Cabe inferir também que a educação como ato de produzir saberes revela-se, numa sociedade tendenciosa, como alienante e ao mesmo tempo instrumento de libertação. Neste sentido, a educação é dialética, cabendo a esta prática social:

É papel da educação em uma sociedade democrática tanto incutir em seus
membros essas coisas comuns quanto ensiná-los a pensar livremente, ou
seja, a estarem abertos à possibilidade de serem diferentes. Para conciliar
essas necessidades contrárias, a alternativa é moldar o indivíduo até certo
ponto e, a partir desse ponto, deixá-lo livre para fazer o que quiser. Se o
indivíduo usar abusivamente sua liberdade, se fizer algo contrário às
crenças, aos costumes básicos daqueles comumente inculcados em todos,
ou seja, se ele cometer alguma imoralidade ou delito, a sociedade procurará
castigá-lo. Em outras palavras, considerando-se a existência de mais de um
conceito de liberdade, a liberdade possível numa democracia é a liberdade
política. (AQUINO, 1997, p. 53)

Por meio da educação, na concepção de Aquino (1997), busca-se o consenso, a vivência coletiva, pois a liberdade é o exercício social da 
responsabilidade, onde todos têm consciência de seus direitos e deveres que valorizam sempre a coletividade. Sabe-se que a democracia e, consequentemente, uma gestão democrática devem se originar no interior de uma escola. Nesse sentido, a escola como campo privilegiado de intervenções políticas e ideológicas traz na sua essência pedagógica a possibilidade de construção de novos paradigmas e práticas que priorizem a vida democrática na escola e na sociedade.

Assim, a democratização institucional torna-se um caminho para que a prática pedagógica se torne efetivamente prática social e possa contribuir para o fortalecimento do processo democrático mais amplo. Como bem já apontou, Paro (1998, p. 46):

[...] tendo em conta que a participação democrática não se dá espontaneamente, sendo antes um processo histórico em construção coletiva, coloca-se a necessidade de se preverem mecanismos institucionais que não apenas viabilizem, mas também incentivem práticas participativas dentro da escola pública.

De acordo com autor supracitado, a escola não é democrática só por sua prática administrativa. Ela torna-se democrática por toda a sua ação pedagógica e essencialmente educativa. No mesmo sentido, não se pode pensar que a gestão democrática da escola possa resolver todos os problemas de um estabelecimento de ensino ou da educação, até mesmo por que se trata de uma prática, ou exercício e não de um modelo preestabelecido a ser seguido.

Uma prática de gestão verdadeiramente democrática de escola prima pela descentralização, que é a transferência de atividades decisórias e não somente administrativas. Entende-se que uma gestão educacional verdadeiramente democrática no espaço escolar se faz como uma prática de exercício da participação e da descentralização das ações educativas e do processo decisório, pois de acordo com Jacobi (1990):

A descentralização significa, em teoria, a possibilidade de ampliação para o exercício dos direitos, a autonomia da gestão municipal, a participação, controle e gestão citadina no seu cotidiano, assim como a potencialização de instrumentos adequado para o uso e redistribuição mais eficiente dos escassos recursos públicos e para reverter às tendências globalizantes dos projetos de planejamento, possibilitando a desburocratização administrativa da agenda. (JACOBI, 1990, p. 08)

No seu sentido original, a participação pressupõe quebra de ruptura, pois depende para sua existência da participação dos entes da comunidade, da autonomia e o exercício dos direitos. Fundamentado nessa ideia, o presente estudo, 
considera a descentralização como conditio sine qua non para que a democracia aconteça não apenas no espaço escolar, mas na sociedade como um todo.

Nesse sentido, é necessário nos dias atuais que se construam instrumentos de gestão que atendam às necessidades da comunidade escolar como um todo, em termos formativos, a partir de aspectos críticos e emancipatórios, o que na prática requer dos gestores um mergulho na identidade particular da identidade que forma a escola sob sua gestão, pois como lembra, Paro (1986, p. 136):

\begin{abstract}
A administração escolar precisa saber buscar na natureza própria da escola e dos objetivos que ela persegue os princípios, métodos e técnicas adequadas ao incremento de sua racionalidade. O exemplo, da empresa a este respeito parece bastante revelador. Se atentarmos para o desenvolvimento histórico da atividade administrativa no interior das empresas, perceberemos que o crescimento de sua racionalidade se deu através do desenvolvimento de técnicas e métodos adequados a sua especificidade e ao alcance dos objetivos.
\end{abstract}

O que o autor está afirmando é que a gestão escolar necessita, para o delineamento de suas ações, conhecer a clientela, ou melhor, a comunidade que forma a instituição que se encontra sob sua gestão, pois isso significa ter clareza sobre os objetivos que a instituição como um todo pretende alcançar. Nesse sentido, ele considera que se faz necessário superar a burocratização que fora importada da administração das empresas para as escolas, deixando de lado a ideia da lucratividade e fortalecendo sempre a finalidade administrativa.

A escola e seu grupo de profissionais estão chamados a superar a concepção tradicional de administração/gestão em que predomina a hierarquia e participação limitada, pois como lembra, Paro (1986, p. 160):

[...] a Administração Escolar atual, pautada pelo autoritarismo em suas relações e pela ausência de participação dos diversos setores da escola e da comunidade em sua realização, não se coaduna com uma concepção de sociedade democrática a que se pretende chegar através da transformação social. Por isso, uma teoria e prática da Administração Escolar que se preocupe com a superação da ordem autoritária na sociedade precisa como horizonte a organização da escola com bases democrática.

Sendo assim, com base no autor acima, consideramos que seja emergente a construção de uma gestão verdadeiramente democrática, pois o que se tem visto são ensaios de democratização do espaço escolar, no qual são limitados os espaços de contribuição e ação da comunidade escolar no que tange ao processo de tomada de decisão.

Nesse sentido, podemos dizer que não há mais espaço para práticas administrativas centralizadoras, verticalizadas, pois isso compromete a qualidade do 
ensino e aprendizagem que são oferecidos pela escola, dada que as finalidades dos sujeitos presentes na escola não caminham na mesma direção. Uma gestão verdadeiramente democrática parte do princípio da participação que é estimulada no ambiente escolar a partir de instrumentos democráticos e de construção e desenvolvimento coletivo que são: Projeto Político Pedagógico (PPP), Conselho Escolar (CE) e Eleição Direta para Diretor (EDD). Os instrumentos citados serão melhor analisados a partir da sessão seguir.

\subsection{Os pressupostos da gestão democrática e sua efetivação na escola.}

É inegável que a forma mais clara de manifestação da gestão democrática é a criação no ambiente escolar de espaços e tempos de participação. É importante lembrar que o termo participação não se limita ao ato de estar presente, mas como lembra Bordenave (1994, p.22), participar se expressa como sendo: "fazer parte, tomar parte ou ter parte". Diferente do que a maioria das instituições escolares tem entendido como participação nas atividades desenvolvidas na escola, a participação está diretamente ligada a uma identificação, ou seja, uma ideia de pertencimento, no sentido do pensar e do fazer nas práticas escolares.

Tem sido comum em pesquisas desenvolvidas por estudiosos como Libâneo (2004) e Veiga (2004) a constatação de que as escolas necessitam se tornar espaços de diálogo e de socialização, no qual os sujeitos que por elas transitam possam se sentir parte ou com o sentimento de pertencimento. Democratizar o processo de gestão, nesse sentido, significa tornar o processo de tomada de decisão acessível a comunidade, pois como ressalta Bordenave (1994), embora existam pessoas que optam por ser representadas pelas outras sem que exerça seu direito de decidir:

[...] a maioria prefere a democracia. E para um crescente número de pessoas, democracia não é apenas um método de governo onde existem eleições. Para elas, democracia é um estado de espírito e um modo de relacionamento entre as pessoas. Democracia é um estado de participação. (BORDENAVE, 1994, p. 08).

Assim como a democracia prescinde da participação, a participação requer espaços democráticos para se solidificar. Nesse sentido, só existe democracia num espaço em que todas as pessoas participam do processo de tomada de decisão e não apenas são convocadas para participar de reuniões para serem informadas sobre as decisões que foram tomadas. Bordenave (1994) lembra que a existência do 
processo eleitora para a gestão não implica necessariamente na democratização da gestão, pois trata-se de um estado de espírito, que a pessoa eleita pode não possuir, de modo a centralizar o processo decisório dentro do espaço escolar.

O gestor democrático é aquele sujeito que organiza o trabalho escolar respeitando a comunidade, trazendo esta, para dentro da escola e possibilitando que seja desenvolvida sua voz ativa. Atuando dessa forma, a comunidade auxilia em todos as ações desde o planejamento até a execução. Nesse sentido, Libâneo (2004) afirma:

\begin{abstract}
A presença da comunidade na escola, especialmente do pais, têm várias implicações. Prioritariamente, os pais e os outros representantes participam do conselho da escola, da associação de pais e mestre (ou organizações correlatas) para preparar o projeto pedagógico-curricular e acompanhar e avaliar a qualidade dos serviços prestados. (LIBÂNEO, 2004, p. 144).
\end{abstract}

Em suas considerações, Libâneo (2004) apresenta o que consideramos como instrumentos necessários à gestão democrática que são: conselho escolar, organização e associação de pais, projeto político pedagógico. Além desses podemos citar ainda, a eleição para gestor e ressaltar que a presença desses instrumentos na escola não assegura que a gestão democrática aconteça, pois tanto, o conselho escolar, como a associação de pais podem não ser atuantes, ou podem ser simplesmente órgãos decorativos e que em nada interferem nos rumos que são seguidos pela escola.

É importante lembrar ainda que participar não consiste numa tarefa fácil, pois implica numa tomada de consciência, que algumas vezes é despertada por sujeitos externos, que desafiam os que se mostram confortáveis e fora do processo de tomada de decisão. Contudo, nesse ato corre-se o risco de sofrer manipulação, pois como alerta Bordenave (1994, p. 28): "[...] às vezes, trata-se de uma participação provocada por agentes externos, que ajudam outros a realizarem seus objetivos [...]". Nesse sentido, uma gestão verdadeiramente democrática envolve o interesse do coletivo e não de uma pessoa ou grupo unicamente, envolve um projeto coletivo que busca a transformação da realidade.

Um caminho eficaz para a materialização da participação é o diálogo, entendido por Fonseca (1995, p. 104) "[...] a arte de ser ensinada e praticada, a comunicação pode ser entendida como elemento norteador da educação para romper com sentimentos inibidores [...]". Uma prática dialógica deve ser o ponto de partida para a democratização do processo de gestão da escola, pois torna o 
processo de tomada de decisão coletivo, assegura a participação e a democracia, não apenas no plano do discurso, mas principalmente no campo prática, da ação.

Uma escola que tem como princípios práticas dialógicas constrói ferramentas críticas que tornam a escola um espaço vivo, dinâmica e participativo. Dentre os instrumentos presentes na escola que podem assegurar a participação da comunidade nos rumos que devem ser seguidos pela escola encontra-se o Projeto Político Pedagógico (PPP).

Veiga (2004) entende que o PPP é o documento de identidade das instituições escolares. É nesse documento que devem estar expressas as principais características dos sujeitos e da instituição, bem como a problemática vivida pela escola e os objetivos e metas que pretendem atingir. Nesse sentido, o PPP configura-se como uma construção permanente, de modo que:

Essa construção será possível por meio de discussões e reuniões que
envolvem toda a comunidade escolar, ou seja, entre equipe administrativa,
financeira e pedagógica, alunos, familiares e comunidade, focando sempre
a melhoria da prática educativa e transformando ideias e concepções em
movimento de ação importantes e fundamentais para o processo de
construção. (VEIGA, 2004, p. 14)

Um projeto político pedagógico comprometido com os sujeitos que integram as práticas pedagógicas/escolares deve ser resultado de inúmeras discussões no qual se busque representar os principais anseios da comunidade escolar em termos de formação. Por meio das discussões por segmento, no qual a equipe diretiva encontra-se em condições de tomada de decisão iguais às demais categorias, é que se constrói uma gestão democrática e se contribuí para a consolidação de um ensino-aprendizagem crítico-transformador.

O exercício de participar do processo de tomada de decisão, faz com que os sujeitos, desenvolvam sua consciência crítica e busquem participar cada vez mais das ações implementadas na escola, como por exemplo a organização do conselho escolar. De acordo com o Programa Nacional de Fortalecimento dos Conselhos Escolares,

O Conselho Escolar, órgão de representação da comunidade educativa [...], trata-se de uma instância colegiada, que deve contar com a participação de representantes dos diferentes segmentos das comunidades escolar e local, podendo constituir um espaço de discussão de caráter consultivo, deliberativo, fiscalizador e mobilizador. (BRASIL, 2004, p. 44).

Verifica-se nas considerações supracitadas que o Conselho Escolar (CE), quando organizado de maneira democrática e participativa, se apresenta como um 
órgão de controle, mobilização e fiscalização. Por meio do CE é que a comunidade participa de maneira mais íntima do processo de tomada de decisão, pois o gestor escolar, embora membro nato, não deve atuar como presidente do órgão, já que é ele quem fiscaliza o trabalho administrativo-financeiro realizado pelo gestor.

Nesse sentido, o CE conta com a participação de todas as categorias que integram o ambiente escolar, por isso deve respeitar cada membro e realizar reuniões periódicas para discutir os rumos que devem ser tomados e os investimentos que devem ser feitos com os recursos decorrentes do PDDE. O CE quando atuante e desprendido das amarradas político-partidárias e das conveniências aproxima cada vez mais a comunidade da escola, pois presta contas à comunidade de tudo que a escola vem adquirindo e de onde são retirados os recursos para tais feitos.

Como salientado, o CE só tem legitimidade quando se manifesta como mobilização da comunidade escolar, de modo a se configurar como o instrumento de maior manifestação da democracia escolar. É por meio do CE que outros instrumentos de natureza democrática podem ser exercitados na escola, como por exemplo, o PPP (já citado) e a eleição direta para diretor (já mencionada, mas que será aprofundada a partir desse momento).

$\mathrm{O} \mathrm{CE}$, quando construindo democraticamente, é condição primeira para que seja implementada na escola a eleição para gestor escolar respeitados, os princípios e normas que são estabelecidos a partir do regimento interno da instituição em comum acordo com a comunidade. Diante do exposto, considera-se que:

A participação efetiva do Conselho Escolar no processo de escolha do
diretor da escola, por exemplo, constitui uma de suas ações de maior
relevância, na medida em que se apresenta como um elemento aglutinador
de forças dos diferentes segmentos que compõem as comunidades local e
escolar. Em algumas escolas, essa participação se dá na organização do
processo ou na forma de consulta, no recebimento de inscrições, na
divulgação das propostas de candidatos, na realização de debates e de
outras atividades definidas pela comunidade escolar e pelo respectivo
sistema de ensino. (BRASIL, 2004, p. 48)

A eleição para diretor/gestor é a forma mais democrática de escolha do sujeito que vai ser responsável por direcionar as ações decididas colegiadamente pela escola, pois cabe ao gestor/diretor, em regime de colaboração, administrar os recursos materiais, financeiros e pedagógicos da instituição escolar.

Nesse sentido, pode-se dizer que na eleição direta, os sujeitos têm a possibilidade de eleger pessoas com quem possuem uma identificação, ou que 
apresentem projetos que se assemelham às necessidades da comunidade. É dessa forma, democrática, participativa e crítica, que se pode construir uma escola mais plural e que atenda as demandas que dela são cobradas diariamente, e que perpassam por uma formação emancipatória que tenha como finalidade primeira a humanização do ser humano.

Logo, pode-se dizer que a construção de uma escola democrática é possível, desde que os princípios da participação estejam assegurados e materializados no espaço escolar, pois sem participação não é possível construir uma escola democrática, já que os rumos assumidos pela escola devem ser uma escolha e compromisso de todos, pois isso representa e solidifica a ideia de pertencimento, do coletivo buscar o melhor para a escola do qual fazem parte.

\section{CONSIDERAÇÕES FINAIS}

A partir dos direcionamentos trazidos pela BNCC, a gestão democrática deve ser implementada em todas as instituições de ensino brasileiras. Contudo, no âmbito prático, as escolas ainda se encontram aparelhadas aos interesses políticos, sendo na maioria das vezes a escolhas dos gestores acontece de forma hierárquica e sem a participação da comunidade escolar. Nesse sentido, nossos esforços se deram no sentido, ao refletir sobre a temática proposta nossos objetivos foram contemplados, pois conseguimos: Analisar os desafios e possibilidades para efetivação da gestão democrática escolar, à medida que refletimos sobre o momento da ditadura militar em que os processos de tomada decisão das instituições escolares eram centralizados e impossibilitavam a participação da comunidade escolar. Com a abertura democrática brasileira em termos políticos e econômicos, a educação vislumbrou práticas que caminhassem no mesmo sentido, embora marcadas pelos interesses do neoliberalismo.

Nesse sentido, foi possível ainda refletir sobre o contexto histórico de produção das concepções democráticas de gestão da sociedade e da escola, pois a ideia de uma gestão democrática não surge do acaso, mas foi produto de todo um arranjo social e interesses externos a própria escola.

Assim, cumprimos também o objetivo de conhecer os desafios para que os processos democráticos da gestão escolar sejam consolidados tal como disciplina a LDB, pois a legislação da educação brasileira disciplina a gestão escolar 
democrática, entretanto, não estabelece os critérios a serem seguidos, deixam a cargo das esferas de governo definirem a forma democrática a ser seguida.

E por fim, identificamos os mecanismos de participação que foram criados para dar visibilidade à gestão democrática, com ênfase nos processos de participação da comunidade escolar, seja na organização do Conselho Escolar autônomo e participativo dos processos de tomada de decisão, seja na escolha do diretor da escola ou ainda da elaboração coletiva e segmentada do projeto político pedagógico.

\section{REFERÊNCIAS}

AQUINO, Jakson Alves de. Democracia e disciplina: as eleições para diretores em escolas públicas. Fortaleza: Universidade Federal do Ceará, 1997. (Monografia).

BOBBIO, Norberto. Democracia. In: SANTILLÁN, José Fernández (org.). Norberto Bobbio: el filósofo y la política. México: Fondo de Cultura Económica, 1996, pp. 229238.

BORDENAVE, J. E. D. O que é participação. São Paulo: Brasiliense, 1994.

BRASIL. Lei de Diretrizes e Bases da Educação Nacional. Lei número 9394, 20 de dezembro de 1996. MEC/SEF; Brasília, 1996.

Ministério da Educação. Conselho Escolar, gestão democrática da educação e escolha do diretor. MEC/SEF. Brasília, 2004.

CORTELLA, M. S. Não espere o Epitáfio - provocações filosóficas. Petrópolis, RJ: Vozes, 2005.

CURY, C.R.J. Federalismo político e educacional. In: FERREIRA, N.S.C. Políticas públicas e gestão da educação: polêmicas, fundamentos e análises. Brasília, DF: Liber Livro, 2006. p. $113-129$.

DALBERIO, Maria Célia Borges. Gestão democrática e participação na escola pública popular. Revista Iberoamericana de Educación. ISSN: 1681-5653 n.ำ47/3 25 de outubro de 2008.

FÁVERO, Osmar; SEMERARO, Giovanni (Orgs). Democracia e Construção do Público no Pensamento Educacional Brasileiro. Petrópolis; Vozes, 2002.

FONSECA, V. Introdução as dificuldades de aprendizagem. 2 ed. Porto Alegre, Artes Medicas, 1995.

JACOBI, Pedro. Descentralização, Participação e Democracia. Educação Municipal. São Paulo: UNDIME, v. 3, № 6, p. 8. jun. 1990. 
LIBÂNEO, José Carlos. Tendências pedagógicas na prática escolar. In:

Democratização da Escola Pública - a pedagogia crítico-social dos conteúdos. São Paulo: Loyola, 2002.

MARQUES, Luciana Rosa. Democracia radical e democracia participativa: contribuições teóricas à análise da democracia na educação. Educ. Soc. vol.29 no.102 Campinas Jan./Apr. 2008.

PARO, Vitor H. Administração Escolar: Introdução Crítica. São Paulo; Cortez, 1986.

Gestão democrática da escola pública. Ática, 1998.

VEIGA, IIma Passos A. (Org). Projeto político-pedagógico: uma construção possível. 17 ed. Campinas: Papirus, 2004. 